\title{
Crowdsourcing Crop Improvement in Sub-Saharan Africa: A Proposal for a Scalable and Inclusive Approach to Food Security
}

\author{
Jacob van Etten*
}

\begin{abstract}
In sub-Saharan Africa, modern varieties released by the formal seed sector cover only a small part of the total crop acreage. Participatory approaches to crop improvement and seed production have been developed to overcome some of the barriers to modern variety development and seed distribution, but have not been widely scaled up. Crowdsourcing, such as seen in online citizen science projects, might inspire new approaches to upscale farmer-participatory seed innovation, specifically aiming at household food production. Using mobile technology, African farmers may be engaged in massively evaluating and distributing seeds. It is argued that a crowdsourcing approach to seed innovation would not only be scalable, but also inclusive through the strengthening of crop diversity as an open informational resource.
\end{abstract}

\section{Introduction}

In sub-Saharan Africa, the great majority of farmers continue to rely on their own crop varieties. Modern varieties cover only a small fraction of the total surface planted to crops and tend to be associated with commercial agriculture. Scaling up the delivery of modern varieties through formal seed systems will not only require a substantial investment in technological capacity but also the expansion of commercially-oriented agriculture, which requires changes in infrastructure and economic policy, which will all take time. In Asia, the dramatic increase in crop land productivity in the second half of the twentieth century relied mainly on the increased use of inputs (industrial fertilisers, water and crop protection products). The introduction of response-sensitive modern varieties was necessary to take full advantage of these higher input levels. Response-sensitive varieties alone will not, however, increase crop productivity substantially if input levels do not increase. In Africa, the use of industrial fertilisers is still limited. Prices tend to be far higher than the world average, due to high transportation costs. Also, irrigation potential is far less developed in the region than in Asia. Therefore, the adoption of modern varieties of most crops remains limited, the major exception being maize production. Improved varieties cover about a third of the total surface planted to maize in sub-Saharan Africa (Morris 1998). For other crops, the numbers are far lower. In technological terms, formal seed systems may have relatively little to offer to improve production of low-input or subsistence crops.

The diverse environments of African agriculture pose important challenges to crop science. In spite of technological advances, plant-breeding still depends on the evaluation of crops in the field (Duvick 1996). Genomics is attracting substantial funding in agricultural research, but plant characterisation and evaluation work seems to lag behind - although the success of genomics work will ultimately depend on the field performance of the resulting phenotypes. Phenotyping requires the labour-intensive work of field evaluation in multiple locations to tease apart genetic and environmental effects on crop performance. Raising technological capacities in plant-breeding in Africa is urgent, but to be effective, these capacities will need to be embedded in working innovation systems. One way to enhance the current research capacity in Africa may be to link 
plant science in smart ways to ongoing innovation, as done by farmers, amplifying the efforts of professional plant-breeders.

If food provision to the most vulnerable households is to be the main focus of seed-based innovation rather than achieving national production goals, seed system interventions will need to focus on the diverse crops that make up African fields and diets. Having a range of crop species and varieties helps farmers cope with environmental limitations by matching varieties to diverse production conditions and diversifying their portfolio to minimise risks. For instance, in a carefully designed study in the highlands of Ethiopia, Di Falco et al. (2010) found strong evidence that increasing varietal diversity increases crop production. The effect was even stronger when rainfall levels were low. On the other hand, crop and varietal diversity may also have direct nutritional effects, independent of productivity. There is strong evidence of a link between dietary diversity and micronutrient intake (reviewed in Frison et al. 2011). Providing more crop diversity to resource-poor farmers can be expected to have a substantial positive effect on the food security of their households.

To improve crops in areas not reached by formal seed systems and to target the diverse environments, crops and varieties of African farmers, several participatory approaches to technology development and diffusion have been developed. Participatory plant-breeding (PPB), participatory variety selection (PVS), community seed banks and seed fairs have been used to foster innovation and access to seeds and diversity in informal seed systems. Also, projects aiming at small-scale, organised seed production have been attempted in order to increase the availability of improved varieties. Essential lessons have been learned from these experiences over the last two decades. However, there has been no breakthrough in upscaling these projects to reach large numbers of farmers.

To take informal seed-based innovation to the next level, interventions following a crowdsourcing approach, facilitated by new information technologies, might prove helpful.

Crowdsourcing is the outsourcing of activities to 'crowds', large numbers of (generally unpaid) volunteers, who contribute with their skills and time to collective efforts. The internet has made it possible to mobilise volunteers without a high upfront investment in institutional organisation. Citizen science projects that make use of crowdsourcing illustrate the potential of mobilising skilled volunteers. In these projects, volunteers have executed tasks such as simple environmental observations, visual recognition of objects, but also complex protein folding exercises that require advanced spatial reasoning (Hand 2010). The level of enthusiasm as well as the quantity and quality of work done by online volunteers in these projects was far beyond initial expectations. It is suggested here that such approaches could inspire the rethinking of participatory approaches to crop innovation in African seed systems. African farmers are gaining increased access to ICT day by day. What would happen if they could become citizen scientists in crop improvement projects?

\section{A proposal}

Obviously, the approaches used in current online citizen science projects are not directly suited for implementation in rural sub-Saharan Africa. For instance, internet access in Africa is still far from universal. Nevertheless, key elements of the philosophy of citizen science approach inspire thinking about distributed approaches to crop innovation. The idea here is to give a tentative account of how a crowdsourced seed innovation system might look, providing enough detail to appreciate its feasibility, but leaving open many aspects of its implementation that would be context specific.

Crowdsourcing seed-based innovation would start with the wide distribution of a large number of small packages of seeds. The varieties would include modern varieties as well as farmer varieties or landraces (collectively referred to as 'varieties' in what follows). Since seed samples would be extremely small (a few grams each), the transport problem would not be of the same order as with conventional, bulky seed lots. Existing distribution networks, such as retail stores, vaccine distribution points, NGOs and churches, could be used to distribute the seed. After farmers grow out the seed samples, they would provide very basic agronomic evaluation data using their mobile telephones.

By 2012, most African villages will be covered by mobile networks (Aker and Mbiti 2010). This radically changes the ways in which information 
can be collected. Automated voice or SMS-based questionnaires can be used by farmers who have access to a mobile telephone. Questionnaires can be administered directly to farmers or with the aid of a field agent if the seeds are distributed through formal channels (agricultural extension services, NGOs). Prior registration (sending the unique identification code on each package to a gratis telephone number) would be crucial to be able to follow-up after crops are harvested. The registration message could be answered with some additional information about the varieties, such as the optimal sowing date, and other crop management instructions.

The incentive structure to engage farmers should revolve around reputation (for instance, 'expert farmer' awards), reciprocity (reinforcement of the idea of contributing to a common pool of resources) and access to information about varieties. Which varieties were tested should only be revealed to farmers after they provide the information about their performance. Making the evaluation of varieties blind should not only make the information more objective. Also, farmers' interest in knowing the name of the variety is an incentive to report back. This may allow them to compare results with other farmers with the same variety or (in the case of a commercialised seeds, which may include both modern varieties and landraces), to purchase more of the same seed. Getting to know the variety name is only an incentive if farmers have a sufficient degree of interest in the process. This can be expected to be associated with greater care in providing information - hence increasing overall data quality. Filtering participants by putting a price on the seed packages, while also potentially increasing data quality, would create barriers that may specifically exclude the poorest households. The system should be made as accessible as possible, to give all farmers the opportunity to participate.

Evaluation systems need to be devised in such a way that noise in the data is reduced to a minimum. Keeping things simple is the key here. Triadic comparisons can be used to elicit preferences (Martin 2004). ${ }^{1}$ Three thumb-sized bags of grain crop seeds could be distributed together as a package, each little bag having a distinctive colour and/or icon as well as a unique identification code. These lots would need to be grown close to each other under the same agroecological conditions. After harvest, farmers provide a preference ranking of the varieties. The resulting data can be analysed with quantitative methods from the emerging field of 'preference learning' (Fürnkranz and Hüllermeier 2011), which are also behind online shopping recommendation systems. If the sample of farmers is large enough and some additional information is solicited as well (why seed lot $\mathrm{A}$ is better than seed lot $\mathrm{B}$, basic information about the trial conditions), not only a ranking scale for different varieties can be reconstructed from the resulting data, but also factors underlying and conditioning the preferences of farmers can be determined.

Additional information on crops and environments can be gathered directly and indirectly. The geographical position of the farmer can be taken into account to evaluate environmental adaptation of varieties. It is technically possible to use mobile phone tracking to obtain the location, although a number of legal and privacy aspects need to be taken into account. Another approach would be to record the point of delivery of seeds. This information could then be incorporated in the analysis to establish if preferences differ among locations and environments.

Farmers could also be asked to provide information about the seeds they currently use and compare their own varieties with the seeds given to them. This would give very relevant information regarding the adoption potential of new seeds. If local seeds prove to be superior, they could be solicited from farmers in order to be included in the next evaluation round. This information would also be crucial in assessing the risk of genetic erosion resulting from the replacement of local cultivars (Guarino 2009). These are new possibilities which could make innovation and conservation truly complementary. It might be that farmer varieties replaced by new varieties in one place are in demand in others. For instance, climate change will make the optimal range of traditional varieties shift. Constant exchange of diverse varieties could help to maintain diversity while transferring seeds along environmental gradients. Priority collection sites to target for $e x$ situ conservation could be determined using this information. Patterns detected in the data would give rise to new questions, leading to targeted field studies to further investigate the innovation process. By making the data openly available 
through the internet, it would be inspected by more analysts and more interesting patterns may be discovered. Scientists could also analyse seed samples with molecular techniques, to provide information that can then be fed back into the system (cf. Richards et al. 2009).

One of the most important uses of the resulting insights is to assist decision-making on seed distribution in the following year. Promising varieties could be tested more widely, while invariably lowly ranked varieties could be discarded and included in ex situ seed collections if their diversity value warrants it. Different clusters may also emerge with consistently divergent preferences. Clusters may be related to environmental or socioeconomic variables. Predictions could then be made about the success of varieties in places they have not yet been tested.

Creating a space in which farmers can contribute with non-monetary resources (i.e. time, skills and small samples of seeds), should provide new opportunities to accelerate innovation. It may also facilitate new forms of collaboration in innovating around crop varieties, both locally and in wider networks. Overall, it can be expected to have an energising effect, with a positive impact on the most food-insecure households.

\section{Beyond seed selection}

A crowdsourcing approach to seed system innovation would build on existing farmer innovation capacities. Understanding the nature of innovation in farmer seed systems is essential in order to bring out its strengths, but also to overcome its limitations. A range of studies shows the potential of African farmers in seed and variety selection. One of the first studies to show that farmers skillfully select seeds was a detailed agricultural ethnography of a village in Sierra Leone by Paul Richards (1986). He described how farmers in Sierra Leone maintain and improve many rice varieties, which they match to local ecologies and take pleasure in playing with diversity. Conscious selection for genetic change is not universal, however, and depends on the crop and its breeding system (Nuijten 2010; Cleveland et al. 2000).

Farmer selection skills have been used as a main entry point to develop alternative approaches to seed innovation. Participatory variety selection (PVS) and participatory plant-breeding (PPB) have been used to increase farmer participation in innovation, in order to go beyond the transfer of technology (ToT) approach. Interventions using farmer-participatory approaches often target a limited number of farmers, who share their skills and time to produce new insights in crop diversity.

As in the ToT approach, varieties developed or identified through participatory methods will then need to spread to other farmers. In the absence of a formal seed delivery system, the capacity for spreading varieties should not be simply assumed. It has been pointed out in the context of Ethiopian seed systems that targeting interventions at variety introduction, seed exchange and storage might be more effective than participatory selection efforts (McGuire 2005). Critical evaluation is needed to determine if seed selection is indeed the most important bottleneck preventing the provision of better seeds to farmers. Modern varieties that are available in some areas may not have had the chance to be distributed to farmers. For instance, in West Africa, although modern rice variety adoption has taken place in several areas, the current presence of these varieties is patchy, not necessarily because these varieties were undesirable, but because variety promotion efforts were intermittent or varieties were lost before they spread (Nuijten 2005). On the other hand, farmer varieties generally show important differences in performance and some merit to be distributed wider.

It may be that the dominant focus on selection skills in PPB/PVS project reflects a cultural bias that identifies creativity mainly with the ex novo discovery of new technologies but less with the adoption of existing elements (Puccio and Chimento 2001). Richards (2009) argues that innovation in farmer seed systems follows a decentralised 'neural network' logic, in which seeds that are deemed to be better than others tend to have a higher survival rates and spread more to other farmers. Selection is not exclusively an individual action, but is also done collectively as seed exchange interactions in social networks change the composition of the genepool over time. The 'neural network' view of innovation contrasts with that of planned innovation, in which varieties are designed to have a number of characteristics and then 'pushed' to be adopted by farmers. 
Crowdsourcing seed innovation would not replace the neural network type of learning, but would further enhance it.

For a 'neural network' type system of innovation to work, farmer exchange and experimentation should both be in place. As for selection skills, the capacities of farmers to enrich the local diversity of crops and varieties vary between areas and crops and among farmers themselves. For instance, in southern Mali, local values of 'good farming' suppose seed self-sufficiency, which makes it culturally undesirable to ask neighbours for seed (Siart 2008). This effectively limits seed exchange and access to diversity. Although farmers tend to take away, stealthily, a few seeds from neighbouring fields to try them out. Here, crowdsourcing seed innovation would help to augment the frequency and geographical scope of farmer seed exchange. Both are helpful to optimise the use of the available diversity and to dynamically adapt to changes in climate, farming systems and socioeconomic conditions. Rather than augmenting the dependency on external innovation and setting in motion a process of deskilling, the crowdsourcing approach would amplify farmers' innovation skills (cf. Stone 2007).

Free sharing of small quantities of seeds is the norm in many parts of the world (Brush 2005). Although free sharing would be far more conducive for continuous experimentation with new seeds, limited sharing of information would force farmers to test the seeds for themselves. This has its own benefits. Imitation is a costefficient shortcut to innovation, compared to more expensive forms of innovation involving observation and experimentation. Imitation may lead to cases of misadoption, however, where adoption is motivated by the social prestige of early adopters rather than the suitability of the innovation (Henrich 2001). Hence, there are advantages associated with limitations in the availability of information about varieties, as long as the seed of these varieties can be tested. Increasing access to test samples of seed should increase innovation through experimentation rather than imitation, as seeds would come with some technical information but without 'social' information. A crowdsourcing approach feeds the information of farmer variety testing from a large number of farmers back into seed distribution efforts and into the local pool of knowledge about varieties, increasing the empirical basis of the 'neural network' and integrating it across different geographical scales.

Learning would not only take place at the 'top' of the system, where data is collected systematically, but also at the 'bottom', as identifying seeds by variety will help farmers to communicate about their findings with neighbours and farmers outside their communities and create a common, better integrated pool of knowledge. Creating an additional flow of information from the top to the bottom by providing summaries of insights derived from the data to local media or to mobile phones ('the 10 most popular varieties', 'best tasting variety', etc.) could spur further discussion around the varieties.

\section{Subsidising information}

Crowdsourcing seed innovation could be seen as an alternative to current major attempts to shift to more intense agricultural input use through subsidies and the provision of small-sized packages of inputs. Malawi's widely publicised input subsidy policy may inspire other countries to implement similar ones (Denning et al. 2009). In the Sahel, micro-dosing of fertilisers was introduced to thousands of farmers (Tabo et al. 2007). Also, several initiatives aim at developing the formal seed sector in parts of Africa. Several seed companies and national agricultural programmes in SSA have adopted the distribution of small packages of seeds. The small package approach has also been adopted by the Alliance for a Green Revolution for Africa (AGRA), which will give the approach a further impetus. The crowdsourcing approach to seed innovation has similar objectives to these approaches, i.e. reaching massive numbers of small-scale African farmers, but there are a number of crucial differences.

An important difference is that crowdsourced seed innovation would specifically target innovation around crop diversity for household food security, especially where market development is incomplete and commercial solutions can be expected to have less impact. Developing markets for agricultural inputs and products in order to raise productivity levels will not automatically improve food security. To increase the nutritional benefits of market development, it will often be necessary to concurrently improve self-sufficient food production (von Braun and Kennedy 1986). Seed commercialisation usually benefits cash crops before it has an impact on local food crops. As a 
general tendency, food crops grown for home consumption receive fewer inputs than cash crops. An excessive reliance on purchased inputs for these crops creates risks for food security when money is not available. Although for commercial crops, informal markets are an important source of seeds, also for poor households (Sperling and McGuire 2010), markets for seeds of crops grown for household production are often missing. The input subsidy approach attempts to overcome missing markets for seeds by artificially reducing transaction costs. The subsidised development of an agro-dealer network is expected to overcome the current low-level equilibrium trap. However, it remains to be seen if this trap will be removed for the most marginal areas. Until now, there has been ample evidence that the approach is far more effective in relatively well-endowed areas than in marginal areas ( $c$. Odame and Muange this IDS Bulletin). In areas with low population densities or bad roads, centralised bulk seed delivery is often not possible logistically or sustainable economically. Developing formal markets may generally be a viable solution to provide seeds of commercial crops, since there is a monetary return on investment. Direct intervention to stimulate the creation of seed businesses may be less effective when seeds and crops remain in a noncommoditised sphere, however, as food is produced for household consumption.

It is important in this context to distinguish between the availability of sufficient seeds and the availability of diverse varieties. In other words, the material aspects (seeds as input) and informational aspects (varieties) of seed provision need to be analysed separately. Crowdsourced seed innovation would imply that crop and varietal diversity are provided through small quantities of seeds to be multiplied by farmers, focusing on the informational aspect of seed innovation at the expense of the material aspect. In the least-developed countries, market imperfections are mainly due to imperfect information (Stiglitz 1989). Agricultural market development in Africa has been enormously stimulated by the lowering cost of information provision due to the expansion of the mobile network and support for agricultural information services (Aker and Mbiti 2010). Implicit and explicit subsidies on information flows are central to welfare in rich countries and take diverse forms, including public libraries, tax rebates to the media and the development of internet infrastructure and access. The internet has given rise to successful, radically new business models that attend a highly diversified demand (Anderson 2006).

Similarly, in sub-Saharan Africa, informational subsidies should be an important ingredient of the mix of development measures targeted at the development of rural markets for diverse seeds in order to increase food security. Crowdsourced seed innovation would stimulate flows of information about varieties, as well as flows of seeds as informational resources. These increased information flows would provide crucial support to develop markets for crop seeds. For instance, the crowdsourced evaluation data could be exploited to measure the potential demand for certain varieties across larger areas. This should help entrepreneurs to identify business opportunities in multiplying and selling seeds.

Hence, specifically subsidising the market for crop diversity (rather than crop seeds per se) may be an important alternative to other types of subsidies currently employed to increase the access to inputs of African farmers. It must be said that the small package approach to commercial seed provision already helps to overcome some of the existing barriers of information exchange, especially those from formal breeders to farmers. Crowdsourcing seed innovation would significantly add to this approach, as it would not only enhance the flow of information from breeders to farmers but also greatly stimulate information flows in the opposite direction. Creating more information symmetry could have an important positive effect on the innovation potential of the agricultural system as a whole. In the case of public spending on crop improvement, it could create greater accountability, as information about the actual seed diversity needs of farmers could be used to calibrate public breeding priorities. Also, to specifically target food security rather than agricultural production, the small package approach should be extended to target non-commercial or 'minor' crops. Free distribution of small seed packages, as suggested here, might be better to target those crops.

Not only would providing information about varieties make seed markets more efficient, but opening spaces for user innovation can also be expected to have a direct positive effect on 
welfare (Henkel and von Hippel 2004). In contrast, subsidies on physical inputs fail to contribute to increased user input in innovation, as they tend to lead to the delivery of a reduced set of technologies in order to reach economies of scale and to respond to political pressures from providers ( $c f$. Chinsinga, this IDS Bulletin). This may lead to suboptimal technology use and a reduction in agricultural and dietary diversity, with detrimental effects on food security (Frison et al. 2011; Di Falco et al. 2010). Subsidising crop seeds as an informational resource, through crowdsourcing and other approaches, however, should increase the diversity of the varieties that are on offer and should have an unequivocally positive effect on food security.

\section{Enhancing the genetic commons}

To ensure the legitimacy of a crowdsourcing approach to seed-based innovation, considerations of transparency and accountability need to be a fundamental part of the basic design. Farmer seed exchange follows the logic of a common heritage regime, in which access is open, but balanced by generalised reciprocity (Brush 2005). Likewise, citizen science is premised on the free sharing of data, which are generally contributed to open databases. Citizen science is most often also 'open' science. Similarly, and to mirror the common heritage regime of plant genetic resources in farmer seed systems, information sharing needs to be fully reciprocal, making the informational resources accessible to all.

Encouraging the free sharing of seed does not contradict market development in rural SSA. Commoditised and non-commoditised exchange can co-exist and may be mutually dependent. This point can be illustrated with developments in another sphere of non-commoditised exchange with interesting parallels to seed innovation: that of open-source software (von Krogh and von Hippel 2006).

Whether certain software is useful for a given problem can often only be determined by trial-anderror, so a number of different solutions need to be explored. Frequently, customisation of different software programmes is required to solve complex problems. This encounters obstacles when software is sold under a commercial licence and is a closed-source. Moreover, commercial software can lead to vendor lock-in, reducing adaptive capacities of technology users.
The good news is that software and its source code are now often made available for free, with a licence to ensure it remains in the common domain. The development of open-source software (OSS) took off when the internet made it possible to engage in continuous online collaboration. An advantage is that users with limited financial resources can now learn to use advanced analytical tools. Lower access barriers have broadened the pool of talent of programmers significantly. The open-source model does not work for all types of software, however. Commercial and free open-source software co-exist, each occupying specific, often complementary niches. OSS is not anti-commercial. But while it is not sold, an intensive network of paid OSS services exists around it to ensure further development, customisation and training of users.

Similarly, seed sharing as done by African farmers does not contradict sustained innovation or market development. In fact, market failures similar to those for specialised software occur. Under marginal production conditions, which implies that the environment is not easily transformed by fertilisation or water management, farmers match their crop varieties to diverse, challenging niches. This increases the difficulty of finding suitable seeds and makes demand for seed highly differentiated.

Information flows are far from perfect, since the potential use of farmer varieties beyond their current range is often not known until it has been tested locally by farmers. Even for known varieties, naming systems are often not entirely consistent and fail to keep track of all varieties. Crowdsourcing might help to communicate the varieties across wider areas as farmers receive consistent information about variety names, hence overcoming information imperfections that stand in the way of market development.

As discussed above, increased information flows may provide information on the market potential of varieties. Seed companies may have an interest in having their own varieties (or even intermediate products) evaluated by crowdsourcing in order to obtain data about their performance and market potential or even to promote them. Opening the network to commercial seeds, under a clear set of rules regarding intellectual property over varieties and data, might help to finance the crowdsourcing network in the long term. On the other hand, seed entrepreneurs might also be interested in gaining access to traditional or 'creolised' varieties that 
farmers identify as superior. Since the seeds would be managed as an open access resource, entrepreneurs could get access to them, albeit under certain intellectual property rights conditions.

As for open-source software, which is protected under licences that ensure the software remains in the public domain, it will be important to provide explicit protection to farmer varieties shared in a crowdsourced seed innovation system. Protection would differ from normal protection in that it avoids exclusive property rights. Also, while material incentives of any substance are most likely counterproductive, as argued above, the public acknowledgement of contributors will be as important as it is for the success of both citizen science projects and the open-source software movement.

\section{Conclusion}

A crowdsourcing approach has the potential to overcome some of the obstacles common to formal seed systems in sub-Saharan Africa, to augment African farmers' innovation skills, to have a direct positive impact on agricultural productivity and food security and to lead to demand-driven (rather than supply-driven) seed market development. It builds on lessons learnt from participatory crop improvement over the last two decades, yet adds an important component to make it possible to

\section{Notes}

* This article benefited from discussions with many colleagues and friends over the last decade, starting with Paul Richards and colleagues at the Technology and Agrarian Development Group at Wageningen University. Paul's 'upscaling' Gedankenexperiment provides an imaginative alternative to marketbased solutions that set in motion the thinking behind this article (Richards 1999). The discussion was kept alive through the weblog on agricultural biodiversity maintained by Luigi Guarino and Jeremy Cherfas (http://agro.biodiver.se/). Robert Hijmans is

\section{References}

Aker, J.C. and Mbiti, I.M. (2010) 'Mobile Phones and Economic Development in Africa', Journal of Economic Perspectives 24.3: 207-32

Anderson, C. (2006) The Long Tail. Why the Future of Business is Selling Less of More, New York: Hyperion von Braun, J. and Kennedy, E. (1986)

Commercialization of Subsistence Agriculture: upscale local efforts to a system that would have an impact on large populations.

This proposal also builds on crucial insights from efforts to provide inputs in smaller formats and in massive ways to overcome market barriers. It provides an important alternative to physical input subsidies, which are unlikely to have a sustained impact, especially in marginal areas.

Whether the proposed approach will work in particular rural African contexts should be evaluated carefully and empirically. Implementation should be organised in stages, iteratively refining the system, starting with tests on a small scale, and building on previous related experiences. In contrast with many other 'pilot' projects in agricultural development, the scope for upscaling the crowdsourcing approach should be clear from the start.

A crowdsourcing approach of this kind could eventually lead to an institutionalised network of innovation that is sustainable in financial terms as well as in terms of the conservation of local varieties. For this, it would be crucial to have in place a balanced intellectual rights regime that in general terms recognises plant genetic resources as an open access resource.

the main culprit of my encounter with opensource software. The involvement of Javier de la Torre and Sergio Alvarez of Madrid-based 'Vizzuality' in a successful citizen science project (www.oldweather.org) created the final piece of the jigsaw. Thanks to all.

1 Triadic comparisons give more information than pairwise comparisons. They make it possible to determine correlations between preferences (farmers who prefer A over B also prefer A over C?). Also, by including two identical seed lots and one that is different, answers could be checked for consistency. However, pairwise comparisons would in principle also work.

Income and Nutritional Effects in Developing

Countries, Working Paper on

Commercialization of Agriculture and Nutrition 1, Washington DC: International

Food Policy Research Institute

Brush, S.B. (2005) 'Protecting Traditional Agricultural Knowledge', Washington University Journal of Law and Policy 17: 59-109 
Cleveland, D.A.; Soleri, D. and Smith, S.E. (2000) 'A Biological Framework for Understanding Farmers' Plant-breeding', Economic Botany 54.3: 377-94

Denning, G.; Kabambe, P.; Sanchez, P.; Malik, A.; Flor, R.; Harawa, R., et al. (2009) 'Input Subsidies to Improve Smallholder Maize Productivity in Malawi: Toward an African Green Revolution', PLoS Biology 7.1: e23

Di Falco, S.; Bezabih, M. and Yesuf, M. (2010) 'Seeds for Livelihood: Crop Biodiversity and Food Production in Ethiopia', Ecological Economics 69.8: 1695-702

Duvick, D.N. (1996) 'Plant-breeding, an Evolutionary Concept,' Crop Science 36: 539-48

Frison, E.A.; Cherfas, J. and Hodgkin, T. (2011) 'Agricultural Biodiversity is Essential for a Sustainable Improvement in Food and Nutrition Security', Sustainability 3.1: 238-53

Fürnkranz, J. and Hüllermeier, E. (eds) (2011) Preference Learning, Heidelberg/Berlin: Springer

Guarino, L. (2009) 'In Which our Blogger Decides not to Quibble about the One Acre Fund', Agricultural Biodiversity Blog, http://agro.biodiver.se/2009/10/in-which-ourblogger-decides-not-to-quibble-about-the-oneacre-fund (accessed 6 April 2011)

Hand, E. (2010) 'Citizen Science: People Power', Nature 466: 685-7

Henkel, J. and von Hippel, E. (2004) 'Welfare Implications of User Innovation', Journal of Technology Transfer 30.1: 73-87

Henrich, J. (2001) 'Cultural Transmission and the Diffusion of Innovations: Adoption Dynamics Indicate that Biased Cultural Transmission is the Predominate Force in Behavioral Change', American Anthropologist 103.4: 992-1013

von Krogh, G. and von Hippel, E. (2006) 'The Promise of Research on Open Source Software', Management Science 52.7: 975-83

Martin, G.J. (2004) Ethnobotany. A Methods Manual, London: Earthscan

McGuire, S. (2005) 'Getting Genes. Rethinking Seed System Analysis and Reform for Sorghum in Ethiopia', PhD thesis, Wageningen University

Morris, M.L. (1998) Maize Seed Industries in Developing Countries, Boulder CO: Lynne Rienner Publishers

Nuijten, E. (2010) 'Gender and Management of Crop Diversity in The Gambia', Journal of Political Ecology 17: 42-58

Nuijten. E. (2005) 'Farmer Management of Gene Flow. The Impact of Gender and Breeding
System on Genetic Diversity and Crop Improvement in The Gambia', $\mathrm{PhD}$ thesis, Wageningen University

Puccio, G.J. and Chimento, M.D. (2001) 'Implicit Theories of Creativity: Laypersons' Perceptions of the Creativity of Adaptors and Innovators', Perceptual and Motor Skills 92 (3 Pt 1): 675-81

Richards, P. (2009) 'Knowledge Networks and Farmer Seeds Systems', in I. Scoones and J. Thompson (eds), Farmer First Revisited: Innovation for Agricultural Research for Development, London: Practical Action Publishing

Richards, P. (1999) 'Casting Seeds to the Four Winds: A Modest Proposal for Plant Genetic Diversity Management', in D.A. Posey (ed.), Cultural and Spiritual Values of Biodiversity, Nairobi and London: UNEP and IT Publications

Richards, P. (1986) Coping with Hunger. Hazard and Experiment in a West African Rice Farming System, London: UCL Press

Richards, P.; De Bruin-Hoekzema, M.; Hughes, S.G.; Kudadjie-Freeman, C.; Kwame Offei, S.; Struik, P.C. and Zannou, A. (2009) 'Seed Systems for African Food Security: Linking Molecular Genetic Analysis and Cultivator Knowledge in West Africa', International Journal of Technology Management 45.1/2: 196-214

Siart, S. (2008) Strengthening Local Seed Systems. Options for Enhancing Diffusion of Varietal Diversity of Sorghum in Southern Mali, Weikersheim: Margraf Publishers

Sperling, L. and McGuire, S. (2010) 'Understanding and Strengthening Informal Seed Markets', Experimental Agriculture 46.02: 119-36

Stiglitz, J.E. (1989) 'Markets, Market Failures, and Development', American Economic Review 79.3: 197-203

Stone, G.D. (2007) 'Agricultural Deskilling and the Spread of Genetically Modified Cotton in Warangal', Current Anthropology 48: 67-103

Tabo, R.; Bationo, A.; Gerard, B.; Ndjeunga, J.; Marchal, D.; Amadou, B.; et al. (2007)

'Advances in Integrated Soil Fertility Management in Sub-Saharan Africa: Challenges and Opportunities', in A. Bationo, B. Waswa, J. Kihara and J. Kimetu (eds), Advances in Integrated Soil Fertility Management in sub-Saharan Africa: Challenges and Opportunities, Dordrecht: Springer 